\title{
The Effect of Diabetes Self- Management Education and Support (DSME/S) on Self-Efficacy in Type 2 Diabetes Mellitus Patients
}

\author{
Authors \\ Arwani $^{1,3^{*}}$, Hardhono Susanto ${ }^{1}$, Dian Ratna Sawitri ${ }^{2}$, Sri Widiyati ${ }^{3}$, Ledwi Wisi Daely ${ }^{3}$ \\ ${ }^{1}$ Post Graduate Program of Medicine and Health Sciences, Faculty of Medicine, \\ Universitas Diponegoro, Indonesia \\ ${ }^{2}$ Faculty of Psychology, Universitas Diponegoro, Indonesia \\ ${ }^{3}$ Politeknik Kesehatan Kemenkes Semarang, Indonesia \\ *Corresponding Author \\ Arwani
}

Post Graduate Program of Medicine and Health Sciences, Faculty of Medicine,

Universitas Diponegoro, Indonesia

\begin{abstract}
Backgrounds: The study aimed at examining the effect of DSME/S on self-efficacy in the client with type 2 diabetes mellitus. Currently, the incidence of type 2 diabetes mellitus worldwide is increasing. Various complications will occur if the management of type 2 diabetes mellitus is not to be performed correctly. Diabetes Self-Management and Support (DSME/S) is an educational activity that can enhance self-efficacy in patients with type 2 diabetes mellitus.

Method: A quasi-experimental research with pre-post test design using control group was applied to 45 samples which were determined using a proportionate simple random sampling technique. Data of the study were analyzed using repeated measure ANOVA.

Results: The results of the study showed that the score of DSME/S had a significant impact on self-efficacy score of the client with type 2 diabetes mellitus compared to DSME group and control group $(p=0.003)$.

Conclusion: DSME/S intervention has a better effect on self-efficacy score in type 2 diabetes mellitus patients compared to DSME intervention. For further research, it is suggested to examine other variables that can affect self-efficacy such as one's mastery experience, social model, verbal persuasion and physical condition and emotional.

Keywords: type 2 Diabetes Mellitus, DSME/S, self-efficacy.
\end{abstract}

\section{Introduction}

The current incidence of diabetes mellitus (DM) shows an increasing phenomenon. This is based on the report of Internal Diabetes Federation (IDF) (2013), that as many as 382 million of the world's population were declared to have diabetes mellitus. The category of diabetes mellitus that was not diagnosed in 2013 was $46 \%$, and it is estimated that the prevalence will continue to increase by 592 million in 2035. This condition is not much different from what happened in Indonesia. This is based on the IDF report (2015), that there are 10 million people with diabetes mellitus in Indonesia in 2015 and the prevalence 
is estimated to increase by 16.1 million people in 2040. Epidemiologically it is estimated that the prevalence of diabetes mellitus reaches 21.3 million people in the year 2030 (Guariguta, 2011). Diabetes mellitus is a non-communicable disease that ranks top. Based on the results of Basic Health Research in 2018, the prevalence of diabetes mellitus in Indonesia has increased from $1.5 \%$ in 2013 to $2 \%$ in 2018 . Based on the results of data from the Health Profiles of Central Java Province in 2017, diabetes mellitus is one of the disease control programs Non-communicable (PTM) is a top priority in Central Java. The number of people with diabetes mellitus in Demak Regency is ranked fourth with the case of NonInsulin Dependent Diabetes Mellitus (NIDDM) as many as 16,721 people. Meanwhile, in 2018 there were 1,567 residents in the Mranggen Health Center area diagnosed with type 2 diabetes mellitus (Judiono, 2017).

Many factors contributed to the increase in the number of diabetes mellitus. According to Diabetes UK (2014), the risk factors for diabetes mellitus include obesity, age, activity physical, unhealthy diet, smoking, blood pressure, stress, lifestyle, family history, gestational diabetes mellitus. Behavioral factors are the most common causes of diabetes mellitus, such as lack of knowledge of nutrition, low physical activity, and unhealthy lifestyles (Hex, 2012).

Diabetes mellitus if not be appropriately managed can cause various complications. Hyperglycemia that occurs in a long period can cause damage to multiple body systems, especially nerves and blood vessels. Complications from diabetes mellitus include the risk of stroke, heart disease, neuropathy, kidney failure, retinopathy diabetic to the risk of death. The risk of death for people with diabetes mellitus, in general, is twice that of nondiabetics. Complicated diabetes mellitus is the third highest cause of death in Indonesia. Therefore efforts are needed to prevent complications due to diabetes mellitus (Kitabchii,2009).

Prevention of complications can be done in various ways. There are four pillars of management to prevent complications of diabetes mellitus, namely education, medical nutrition therapy, physical exercise and pharmacological interventions (Al Khawaldeh, 2009). Programs that have been implemented in Indonesia today are specifically health programs in health centers in dealing with diabetes mellitus, namely Chronic Disease Management program, Development Post Integrated, and Healthy Living Community Movement. But the application is considered to be still not optimal in preventing an increase in diabetes mellitus.

Type 2 diabetes mellitus is one type of diabetes mellitus which is mostly due to wrong behavior factors. Therefore efforts to deal with type 2 diabetes mellitus are focused on the process of behavior change, one of which is through the Diabetes approach Self Management Education and Support (DSME / S). According to the American Diabetes Association (ADA) (2014), DSME / $\mathrm{S}$ is a way to change the behavior and maintain the health of patients with type 2 diabetes mellitus. DSME / S has advantages such as structured programs, regulating standards, specific curriculum, and empower type 2 diabetes mellitus patients independently. Besides that, DSME / S is a support that helps in implementing, maintaining and monitoring the behavior of people with diabetes mellitus (Seaquist, 2013).

DSME / S has a direct relationship with selfefficacy. Self-efficacy is an essential element in managing diabetes mellitus sufferers. The virtue of self-efficacy for people with diabetes mellitus is to encourage people with diabetes mellitus to manage their disease independently. According to research conducted by King (2010), there is a significant relationship between self-efficacy and adherence to treatment of type 2 diabetes mellitus, so that complications that may occur in type 2 diabetes mellitus can be minimized. The study by Philis (2014) concluded that the application of DSME in discharge planning had a significant influence in increasing the self-efficacy of patients with type 2 diabetes mellitus. 


\section{Method}

The research design used was a Quasi-Experiment with a pre-post test design using a control group. The population in this study were patients with type 2 diabetes mellitus in the Area Mranggen I Health Center Working, Demak district, province Central Java. The sample size for this study was 45 respondents. The research sample was taken using proportional simple random sampling technique.
In this study, the characteristics studied were gender, occupation, and education in the three research groups described through frequency distribution tables and percentages. While the age variable, the level of self-efficacy in the DSME / S group and the controls were described as mean and standard deviation (data were normally distributed), while in the DSME group it was illustrated with a median, minimum and maximum value (data not normally distributed). Data were analyzed using test repeated measure ANOVA.

\section{Results and Discussion}

Table 1 Distribution of Frequency Characteristics of Respondents based on age, gender, education history and employment in type 2 DM clients $(n=45)$

\begin{tabular}{|c|c|c|c|c|}
\hline \multirow{2}{*}{$\begin{array}{l}\text { Characteristics } \\
\text { Respondents }\end{array}$} & \multicolumn{3}{|c|}{ Group } & \multirow[b]{2}{*}{$P$} \\
\hline & $\begin{array}{c}\text { DSME / S } \\
(\mathrm{n}=15)\end{array}$ & $\begin{array}{l}\text { DSME } \\
(\mathrm{n}=15)\end{array}$ & $\begin{array}{l}\text { Control } \\
(\mathrm{n}=15)\end{array}$ & \\
\hline Age & $53.20 \pm$ & $4.69352 .93 \pm 10.089$ & $56.00 \pm 7.663$ & 0.627 \\
\hline Sex & & & & 0.280 \\
\hline Male & $1(6.7)$ & $4(26.7)$ & $5(33.3)$ & \\
\hline Female & $14(93.3)$ & $11(73.3)$ & $10(67.7)$ & \\
\hline Education Status & & & & 0.756 \\
\hline Elementary & $10(66.7)$ & $13(86.7)$ & $12(80.0)$ & \\
\hline Junior High School & $2(13.3)$ & $1(6.7)$ & $1(6.7)$ & \\
\hline Senior High School & $3(20.0)$ & $1(6.7)$ & $2(13.3)$ & \\
\hline Employment & & & & 0.131 \\
\hline Unemployed & $4(26.7)$ & $9(60.0)$ & $11(73.3)$ & \\
\hline Farmers & $4(26.7)$ & $2(13.3)$ & 0 & \\
\hline Traders & $3(20.0)$ & $3(20.0)$ & $3(20.0)$ & \\
\hline Private & $2(13.3)$ & 0 & 0 & \\
\hline Entrepreneurs & $1(6.7)$ & $1(6.7)$ & 0 & \\
\hline Labor & $1(6.7)$ & 0 & $1(6.7)$ & \\
\hline
\end{tabular}

Characteristics of respondents based on age showed that the average age of respondents in the DSME / S group was 53.20 years, DSME was 52.93 years and control was 56.00 years. According to Sue (2012), that with increasing age, the number of productive beta cells decreases so that the risk of type 2 diabetes mellitus, especially at the age of more than 45 years. Most of the research respondents were female, namely in the DSME / S group as many as 14 (93.3\%), DSME as many as $11(73.3 \%)$ and controls as many as 10 (67.7\%). Following the opinion of Franek (2013), that women suffer more from type 2 diabetes mellitus compared to men because it is associated with pregnancy in women which is a risk factor for the occurrence of diabetes mellitus so that it has an opportunity to increase body mass index. Characteristics of respondents based on education show that the education level of the last respondent from the three groups is the majority of elementary school graduates as much as 35 (77.8\%). This indicates that in general respondents were of low educational background. According to Bonner (2010), the lower the level of education of a person, the more difficult it is to prevent complications due to type 2 diabetes mellitus due to lack of information and renewal regarding type 2 diabetes mellitus. Higher education will have an impact on the quality of knowledge. Following the opinion of Chrvala 
(2016), the higher the level of education of people with diabetes mellitus, the better the patient's understanding of adherence to taking medication. Characteristics of respondents based on the type of work in the three groups the majority of respondents did not work namely 24 (53.3\%). Based on the results of the Chopola (2016), people who tend to get diabetes are people who don't work. Physical activity is essential in the prevention of diabetes mellitus. People who do not do physical exercise or do not work tend to do less physical activity so that the metabolic processes in the body do not go well.

Table 2 An overview of the self-efficacy score of type 2 DM patients before and after DSME / S, DSME, and control treatment $(n=45)$.

\begin{tabular}{lccccc}
\hline Group & \multicolumn{5}{c}{ Self-efficacy } \\
\cline { 2 - 6 } & Before & $p$ & After & $p$ & Gap \\
\cline { 2 - 6 } DSME/S & $60.53 \pm 13.69$ & 0.182 & $85.53 \pm 8.69$ & 0.003 & 25 \\
DSME & $78(43-87)$ & & $85(49-95)$ & & 7 \\
Control & $62.13 \pm 16.87$ & & $59.67 \pm 17.52$ & & -2.46 \\
\hline
\end{tabular}

Based on Table 2, it shows that the mean score of self-efficacy initial (pretest) in the three groups was not significantly different. While the results of the second measurement (posttest) increased from 60.53 to 85.53 (DSME / S), and from 78 to 85 (DSME), where the increase was statistically significant $(p=0.003)$. Increasing the score of self-efficacy in the two treatment groups (DSME / $\mathrm{S}$ and DSME) was categorized as self-efficacy very high (Sarkar, 2010).

The increased score is self-efficacy influenced by several factors. According to Strom (2012), selfefficacy can be controlled by mastery experience, vicarious experience, verbal persuasion, and physical and emotional conditions. Some of these factors affect a person's cognitive process so that the emergence of a sense of motivation to achieve the expected goals. According to Young (2016), self-efficacy in patients with diabetes mellitus was formed because of individual beliefs and motivations that arouse individuals to heal independently so that patients can behave to support improvements in their disease management such as dieting, physical exercise control blood sugar levels and prevention of other diabetes mellitus.

Table 3 Repeated measure ANOVA analysis of comparison of self-efficacy scores between groups before and after the action $(n=45)$

\begin{tabular}{lcc}
\hline Treatment & mean \pm SD & $P$ \\
\hline Pre test & & 0.003 \\
DSME/S & $60.53 \pm 13.69$ & \\
DSME & $78(43-87)$ & \\
Control & $62.13 \pm 16.87$ & \\
\hline Post Test & & \\
DSME/S & $85.53 \pm 8.69$ & \\
DSME & $85(49-95)$ & \\
Control & $59.67 \pm 17.52$ & \\
\hline
\end{tabular}

Based on Table 3, it is known that the intervention had a significant effect on the score self-efficacy $(\mathrm{p}=0.003)$. This can be possible because of the influence of the response. Factors that influence self-efficacy include mastery experience, social models, verbal persuasion, and physical and emotional conditions. High self-efficacy in type 2
DM patients is affected by behavior change process factors; one of them is through the DSME / $\mathrm{S}$ approach. However, if based on the difference in scores, then the DSME / S intervention group had a higher increase in variance than the DSME intervention group at 25 versus 7 (Krichbaum, 2013). 

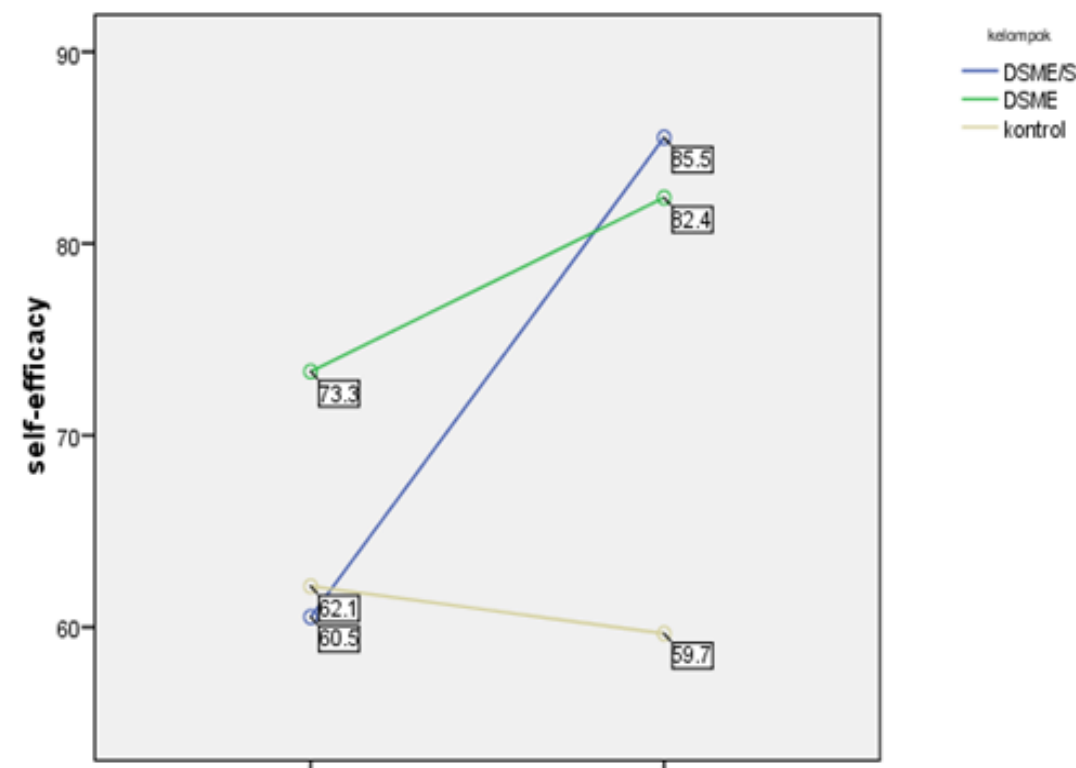

Figure 1 Measurement Score of Self-efficacy initial and final

Based on Figure 1, it was shown that the scores self-efficacy in the DSME / S and DSME groups increased, but the increase in the score selfefficacy in the DSME / $\mathrm{S}$ group was more significant than the DSME treatment group alone. Whereas in the control group, the level of score self-efficacy has decreased. This shows that interventions (DSME / S and DSME) have an impact on changes in the rating of self-efficacy in patients with type 2 diabetes mellitus.

Diabetes Self Management and Support (DSME / $\mathrm{S})$ is a combination of diabetes self-management education (DSME) and diabetes self. Management-Support (DSMS). DSME is a program that facilitates the knowledge, skills, and abilities needed for diabetes self-care. DSME activities will influence the establishment of sources of self-efficacy, namely Performance Accomplishment and Vicarious experience. While DSMS is one of the supports obtained from people closest to type 2 diabetes mellitus clients, one of which is family support (Ianoti, 2003). Family support is an attitude of action which states that the most reliable indicator has a positive impact on the self-care of patients with diabetes mellitus. The advantages of DSME / S lies in the element of $S$ that support is a support that assists in implementing, maintaining and monitoring the behavior of diabetes mellitus.
Support is also obtained from sources of selfefficacy, namely verbal persuasion, and emotional arousal thus affecting the process of increasing scores self-efficacy (Mayberry, 2015).

The results of this study are consistent with previous studies conducted by Strom (2012), on the Effect of the DSME Program on Self Management in Patients with Type 2 diabetes mellitus, where DSME influences selfmanagement of type 2 diabetes mellitus patients. Another study by Tabashi (2014), on Characteristics, Family Support and Self-Efficacy on the Age of Type 2 diabetes mellitus concluded that increasing self-efficacy in managing type 2 diabetes mellitus in the elderly is functional if able to accept the condition accompanied by family support good $(\mathrm{p}=0.008)$. The results of the study by Vacaro (2014), about the Effect of DSME / S on Diabetes Distress in patients with type 2 diabetes mellitus in concluded that DSME / S can reduce diabetes distress in patients with type 2 diabetes mellitus $(\mathrm{p}=0.001)$.

\section{Conclusions}

The results of this study prove that Diabetes SelfManagement Education and Support (DSME / S) has a significant influence towards the selfefficacy of type 2 Diabetes Mellitus clients in the Mranggen I Health Center area, Demak district, 
Central Java - Indonesia. Developing diabetes interventions with family support is an integral part of sustaining self-management behaviors and improving the health outcomes of T2D patients. In conclusion, this systematic review found that DSME with family support improves health outcomes for patients with uncontrolled glycemia. Further study needs to provide details of DSME in the intervention and compare the health outcomes with and without family involvement in DSME programs.

\section{References}

1. American Association of Diabetes Educators, 2009. AADE guidelines for the practice of diabetes self-management education and training (DSME/T). The Diabetes Educator, 35(3_suppl), pp.85S107S.

2. Al-Khawaldeh, O.A., Al-Hassan, M.A. and Froelicher, E.S., 2012. Self-efficacy, self-management, and glycemic control in adults with type 2 diabetes mellitus. Journal of Diabetes and its Complications, 26(1), pp.10-16.

3. Atlas, D., 2015. International diabetes federation. IDF Diabetes Atlas, 7th edn. Brussels, Belgium: International Diabetes Federation.

4. Bonner, J.E., 2010. Social-cognitive predictors of physical activity initiation in type 2 diabetes following diabetes selfmanagement education: application of the health action process approach.

5. Chrvala, C.A., Sherr, D. and Lipman, R.D., 2016. Diabetes self-management education for adults with type 2 diabetes mellitus: a systematic review of the effect on glycemic control. Patient education and counseling, 99(6), pp.926-943.

6. Coppola, A., Sasso, L., Bagnasco, A., Giustina, A., and Gazzaruso, C., 2016. The role of patient education in the prevention and management of type 2 diabetes: an overview. Endocrine, 53(1), pp.18-27.
7. Franek, J., 2013. Self-management support interventions for persons with chronic disease: an evidence-based analysis. Ontario health technology assessment series, 13(9), p.1.

8. Guariguata, L., Whiting, D., Weil, C. and Unwin, N., 2011. The International Diabetes Federation diabetes atlas methodology for estimating the global and national prevalence of diabetes in adults. Diabetes research and clinical practice, 94(3), pp.322-332

9. Hex, N., Bartlett, C., Wright, D., Taylor, M. and Varley, D., 2012. Estimating the current and future costs of Type 1 and Type 2 diabetes in the UK, including direct health costs and indirect societal and productivity costs. Diabetic Medicine, 29(7),pp.855-862.

10. Iannotti, R.J., Schneider, S., Nansel, T.R., Haynie, D.L., Plotnick, L.P., Clark, L.M., Sobel, D.O. and Simons-Morton, B., 2006. Self-efficacy, outcome expectations, and diabetes self-management in adolescents with type 1 diabetes. Journal of Developmental \& Behavioral Pediatrics, 27(2), pp.98-105.

11. Judiono, J., Hadisaputro, S., Indranila, K.S., Cahyono, B., Suzery, M., Widiastuti, Y. and Purnawan, A.I., 2014. Effects of plain kefir on biomolecular aspects of the glycemic status of type 2 diabetes mellitus (T2DM) patients in Bandung, West Java [study on human blood glucose, c peptide, and insulin]. Functional foods in health and disease, 4(8), pp.340-348.

12. Kautzky-Willer, A., Harreiter, J. and Pacini, G., 2016. Sex and gender differences in risk, pathophysiology, and complications of type 2 diabetes mellitus. Endocrine reviews, 37(3), pp.278-316.

13. Kitabchi, A.E., Umpierrez, G.E., Miles, J.M. and Fisher, J.N., 2009. Hyperglycemic crises in adult patients 
with diabetes. Diabetes Care, 32(7), pp.1335-1343.

14. King, D.K., Glasgow, R.E., Toobert, D.J., Strycker, L.A., Estabrooks, P.A., Osuna, D. and Faber, A.J., 2010. Self-efficacy, problem-solving, and social-environmental support are associated with diabetes selfmanagement behaviors. Diabetes Care, 33(4), pp.751-753.

15. Krichbaum, K., Aarestad, V. and Buethe, M., 2003. Exploring the connection between self-efficacy and effective diabetes self-f management. The Diabetes Educator, 29(4), pp.653-662.

16. Mayberry, L.S., and Osborn, C.Y., 2012. Family support, medication adherence, and glycemic control among adults with type 2 diabetes. Diabetes Care,35(6), pp.12391245.

17. Philis-Tsimikas, A. and Gallo, L.C., 2014. Implementing community-based diabetes programs: the Scripps Whittier diabetes institute experience. Current diabetes reports, 14(2), p.462.

18. Sarkar, U., Fisher, L. and Schillinger, D., 2006. Is self-efficacy associated with diabetes self-management across race /ethnicity and health literacy?. Diabetes Care, 29(4), pp.823-829.

19. Seaquist, E.R., Anderson, J., Childs, B., Cryer, P., Dagogo-Jack, S., Fish, L., Heller, S.R., Rodriguez, H., Rosenzweig, J. and Vigersky, R., 2013. Hypoglycemia and diabetes: a report of a workgroup of the American Diabetes Association and the Endocrine Society. The Journal of Clinical Endocrinology \& Metabolism,98(5), pp.1845-1859.

20. Sue Kirkman, M., Briscoe, V.J., Clark, N., Florez, H., Haas, L.B., Halter, J.B., Huang, E.S., Korytkowski, M.T., Munshi, M.N., Odegard, P.S. and Pratley, R.E., 2012.
Diabetes in older adults: a consensus report. Journal of the American Geriatrics Society, 60(12), pp.2342-2356.

21. Strom, J.L. and Egede, L.E., 2012. The impact of social support on outcomes in adult patients with type 2 diabetes: a systematic review. Current diabetes reports, 12(6), pp.769-781.

22. Tabasi, H.K., Madarshahian, F., Nikoo, M.K., Hassanabadi, M. and Mahmoudirad, G., 2014. Impact of family support improvement behaviors on antidiabetic medication adherence and cognition in type 2 diabetic patients - Journal of Diabetes \& Metabolic Disorders, 13(1), p.113.

23. Vaccaro, J.A., Exebio, J.C., Zarini, G.G. and Huffman, F.G., 2014. The role of family/friend social support in diabetes self-management for minorities with type 2 diabetes.

24. Young-Hyman, D., De Groot, M., HillBriggs, F., Gonzalez, J.S., Hood, K. and Peyrot, M., 2016. Psychosocial care for people with diabetes: a position statement of the American Diabetes Association. Diabetes Care, 39(12), pp.2126-2140. 